\title{
Uncovering molecular events associated with the chemosuppressive effects of flaxseed: a microarray analysis of the laying hen model of ovarian cancer
}

\author{
Karen H Hales ${ }^{1 *}$, Sheree C Speckman ${ }^{2}$, Nawneet K Kurrey ${ }^{2,3}$ and Dale B Hales ${ }^{1,2}$
}

\begin{abstract}
Background: The laying hen model of spontaneous epithelial ovarian cancer (EOC) is unique in that it is the only model that enables observations of early events in disease progression and is therefore also uniquely suited for chemoprevention trials. Previous studies on the effect of dietary flaxseed in laying hens have revealed the potential for both amelioration and prevention of ovarian cancer. The objective of this study was to assess the effect of flaxseed on genes and pathways that are dysregulated in tumors. We have used a bioinformatics approach to identify these genes, followed by qPCR validation, immunohistochemical localization, and in situ hybridization to visualize expression in normal ovaries and tumors from animals fed a control diet or a diet containing 10\% flaxseed.

Results: Bioinformatic analysis of ovarian tumors in hens led to the identification of a group of highly up-regulated genes that are involved in the embryonic process of branching morphogenesis. Expression of these genes coincides with expression of E-cadherin in the tumor epithelium. Levels of expression of these genes in tumors from flax-fed animals are reduced 40-60\%. E-cadherin and miR200 are both up-regulated in tumors from control-fed hens, whereas their expression is decreased $60-75 \%$ in tumors from flax-fed hens. This does not appear to be due to an increase in ZEB1 as mRNA levels are increased five-fold in tumors, with no significant difference between control-fed and flax-fed hens.
\end{abstract}

Conclusions: We suggest that nutritional intervention with flaxseed targets the pathways regulating branching morphogenesis and thereby alters the progression of ovarian cancer.

Keywords: Ovarian cancer, Laying hen, Flaxseed, Branching morphogenesis

\section{Background}

One out of 71 women will develop ovarian cancer in her lifetime. The five year survival rate is less than $44 \%$, making ovarian cancer the most lethal gynecologic malignancy. This number has not changed significantly in the last 20 years in spite of advances in platinum-based chemotherapy [1]. For this reason, there is a critical need to explore effective chemoprevention strategies.

It has been estimated that at least $30 \%$ of all cancers could be prevented through diet, exercise, and maintaining a healthy weight [2]. One outcome of this

\footnotetext{
* Correspondence: khales@siumed.edu

'Department of Obstetrics and Gynecology, Southern Illinois University at Carbondale, School of Medicine, Life Science III, (M/C 6512), 1135 Dr.,

Carbondale, Lincoln, IL 62901, USA

Full list of author information is available at the end of the article
}

approach is the reduction of the chronic, low-grade systemic inflammation that accompanies obesity. Chronic inflammation has been implicated to play a causative role in many diseases, including cancer [3]. Further reduction of inflammation can be achieved by lowering the ratio of omega- 6 to omega- 3 fatty acids. The modern western diet contains a high ratio of omega- 6 to omega- 3 fatty acids, a profile that is both pro-inflammatory and oxidant-rich and creates an environment conducive to the development of disease. Flaxseed is one of the richest plant sources of omega-3 fatty acids. In addition, flaxseed also contains lignans, a class of phytoestrogens that also act as antioxidants [4]. These two different nutriceuticals have pathway-specific actions, targeting inflammation and oxidative damage.

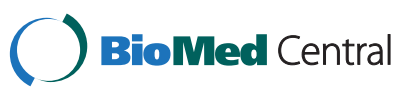


Research into the etiology of ovarian cancer has been limited by the lack of suitable animal models. The laying hen is a robust model in that ovarian cancer develops spontaneously with pathological and histological presentation very similar to human disease $[5,6]$. As in women, the average age of onset occurs later in reproductive life, with $40 \%$ of hens having the disease by six years of age [7]. The disease can progress rapidly, with transcoelomic spread disseminating from the ovary to organs and peritoneal surfaces, and with the accumulation of ascites. The four histotypes observed in human are represented in the hen, although the endometrioid type is the predominant form found in the hen whereas the serous type is most prevalent in women [8]. Mutations in p53 are common in epithelial ovarian cancer (EOC) from both species [9]. Numerous characteristic markers are also shared between the tumors of the two species such as CA-125 [10], CYP1B1 [11], E-cadherin [12] and COX-1 [13]. The expression of COX-1 and accompanying high levels of prostaglandin E2 presents a target for dietary intervention with omega-3 fatty acids. Our one year study of hens fed a diet of $10 \%$ flaxseed showed reduction in cancer severity that corresponded to a reduction in prostaglandin levels [14]. This suggests that ovarian cancer progression may be driven by inflammation. Our long term study in which hens were fed a diet supplemented with $10 \%$ flaxseed for four years resulted in a significant decrease in both incidence and severity of ovarian cancer [15]. This suggests that in addition to decreased progression, initiation and/or promotion of this disease may be slowed by some component of flaxseed. This data is dually important in that it highlights the utility of the hen model for use in dietary studies of chemoprevention, and it provides strong evidence that dietary flaxseed significantly affects the initiation, promotion and progression of ovarian cancer. Thus, identification of the pathways altered by flaxseed may give insight into the etiology of the disease.

The objective of the current study was to identify possible targets and pathways affected by dietary flaxseed and by ovarian cancer to determine the mechanisms by which flaxseed confers chemoprotection against ovarian cancer. We performed a microarray analysis which compared normal ovaries and ovarian tumors from hens fed a control diet to those of hens fed a diet supplemented with $10 \%$ flaxseed. Microarray analysis was followed by comprehensive bioinformatics and several levels of experimental validation. This analysis revealed that pathways associated with branching morphogenesis are significantly increased in ovarian cancer and reduced by flaxseed, suggesting that the process driving tumor growth and progression toward a glandular morphology are targeted by the biologically active constituents of flaxseed.

\section{Results and discussion}

Flaxseed modulates genes linked to ovarian cancer in the laying hen

To evaluate the genome-wide effect of flaxseed in ovarian cancer, we conducted microarray and bioinformatics analyses. The Agilent custom 4x44K chicken long oligo microarray [16] was utilized for this study based on 2X2 experimental conditions, i.e. diet (control \& flaxseed enriched) and tissue (normal \& cancer). The samples were obtained from the one year flaxseed study [14]. We performed a 6-way pair analysis of the gene list between the following groups: 1 . Control Cancer (CC) to Control Normal (CN); 2. Control Cancer to Flax Normal (FN); 3. Flax Normal to Flax Cancer (FC); 4. Flax Cancer to Control Normal; 5. Control Normal to Flax Normal; 6. Flax Cancer to Control Cancer (Figure 1). The gene expression pattern in each analysis group is distinct and separates one group expression pattern from another, suggesting the effect of flaxseed is diverse at the gene level (Figure 2). This result encouraged us to focus on specific sets of genes which are linked to cancer progression. Annotated genes used in the $4 \mathrm{X} 44 \mathrm{~K}$ arrays were classified based on their biological and molecular pathways using a pathway analysis tool which yielded 337 genes (list of genes in Additional file 1) related to the pathogenesis of ovarian cancer [17]. Further, we measured the expression of these 337 genes in the $\mathrm{CC}, \mathrm{CN}$, FN, \& FC groups and pair wise analyses were carried out between the groups (Figure 2). Comparing the expression in different sample groups suggests that the group fed with flaxseed downregulated cancer promoting pathways such as angiogenesis, VEGF signaling, endothelin signaling, WNT signaling, cadherin signaling, inflammation and oxidative stress signaling. Similarly, tumor suppressor pathways such as p53 signaling, apoptosis signaling, cell cycle, and JAK/STAT signaling were upregulated, indicating that the flaxseed acts as an overall tumor suppressor by negatively regulating the ovarian cancer associated pathways and promoting tumor suppressor pathways.

\section{Microarray identification of genes responsive to flaxseed}

In order to identify the genes which may be directly linked with ovarian cancer progression, a comparison was made of all cancer groups (control cancer and flax cancer) to all normal groups (control normal and flax normal) i.e. CC-CN to FC-FN, CC-CN to FC-CN and FC-FN to CC-FN. This exercise generated 324 upregulated genes and 287 downregulated genes which were common in both cancer groups (control cancer and flax cancer), indicating that their differential expression may be involved in ovarian cancer pathogenesis (Figure 3). In order to examine the flaxseed responsive genes, we filtered and sorted a list of 118 genes (see material \& 


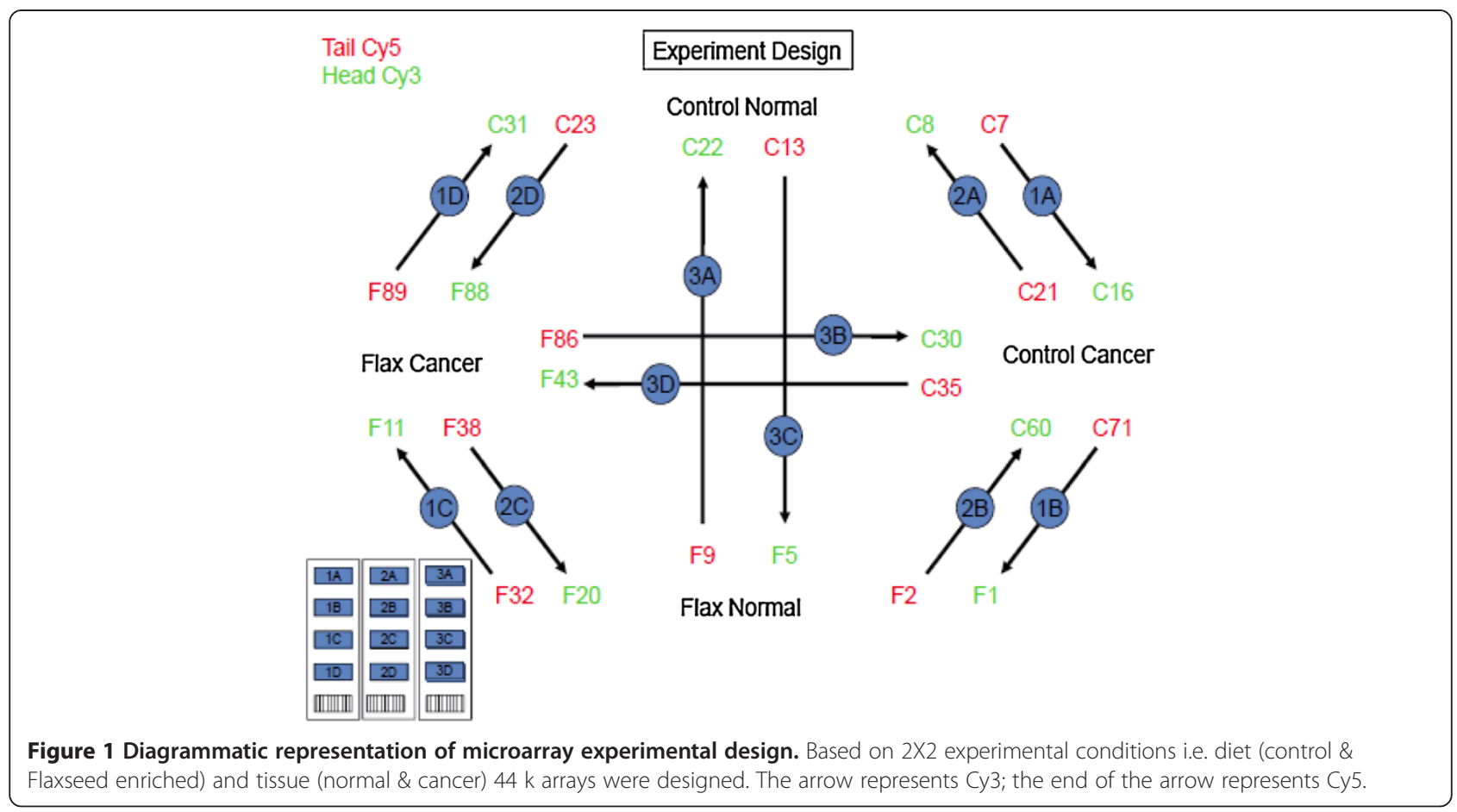

methods) from our microarray analysis which are involved in ovarian cancer and may be targets of flaxseed. Further examination of the expression levels of these 118 genes in CC-CN and FN-CN (Additional file 2) revealed that there is differential expression between the groups. The genes exhibit a difference in magnitude of expression (fold change), indicating that the degree of difference in expression is crucial for cancer progression (Figure 3). Genes that are upregulated in cancer are also increased in tumors from flax-fed animals but not to the same extent. This is in agreement with earlier observations demonstrating that the expression of certain genes above a critical threshold plays a protective role against carcinogenesis but their aberrant expression beyond this critical level may have an adverse effect [18]. Comparison of 118 genes between flax-normal vs. control-cancer showed that most of these genes have significant differences in their expression levels.

Real time PCR validation corroborates flaxseed responsive genes found by microarray analysis

To validate our microarray analysis, we evaluated the mRNA levels of 44 genes by PCR-array. These were representative genes identified by pathway analysis to be involved in angiogenesis, signaling (wnt, integrin, cadherin, JAK/STAT, Notch, VEGF pathways), cell cycle, apoptosis, inflammation, oxidative stress and developmental pathways (Table 1). Figure 4 shows the expression of 22 genes in each sample group. The level of gene expression of these genes quantified by qPCR significantly matches with the array results (not shown). Of the 22 genes not shown, four are the house keeping genes used for normalization, five were selected for further validation, and 13 were not significantly different between groups. One of the important observations of the study was that the wellestablished cancer promoting and inflammatory genes like IL2, VEGF1, IGF1, PTGS1, cMYC and CCDN1 [19] were modulated by flaxseed compared to control-fed hens. Reduction in the expression of these inflammatory genes suggests that flaxseed mitigates cancer promoting activities and acts as an anticancer agent. Stemness-associated genes KLF4, OCT4 and SOX2 [20] were also analyzed. SOX2, KLF4 and OCT4 were elevated in tumors from control-fed hens. However, in tumors from flax-fed hens, only $S O X 2$ was greatly reduced whereas both KLF4 and OCT4 expression was enhanced. Thus, flaxseed did not have a uniform effect on the expression of genes associated with stem cells.

\section{E-cadherin, PAX2, MSX2, FOXA2 and Engrailed-1 are upregulated in hen ovarian cancer and decreased by dietary flaxseed}

The gene that showed the greatest induction by the microarray analysis was E-cadherin, with a 44-fold increase in tumors compared to normal ovary. Upregulation of E-cadherin expression is one of the earliest events in the development of EOC and is common to all ovarian cancer histotypes [21]. This E-cadherin pattern could potentially have diagnostic value, but more importantly, identifying factors that regulate E-cadherin 


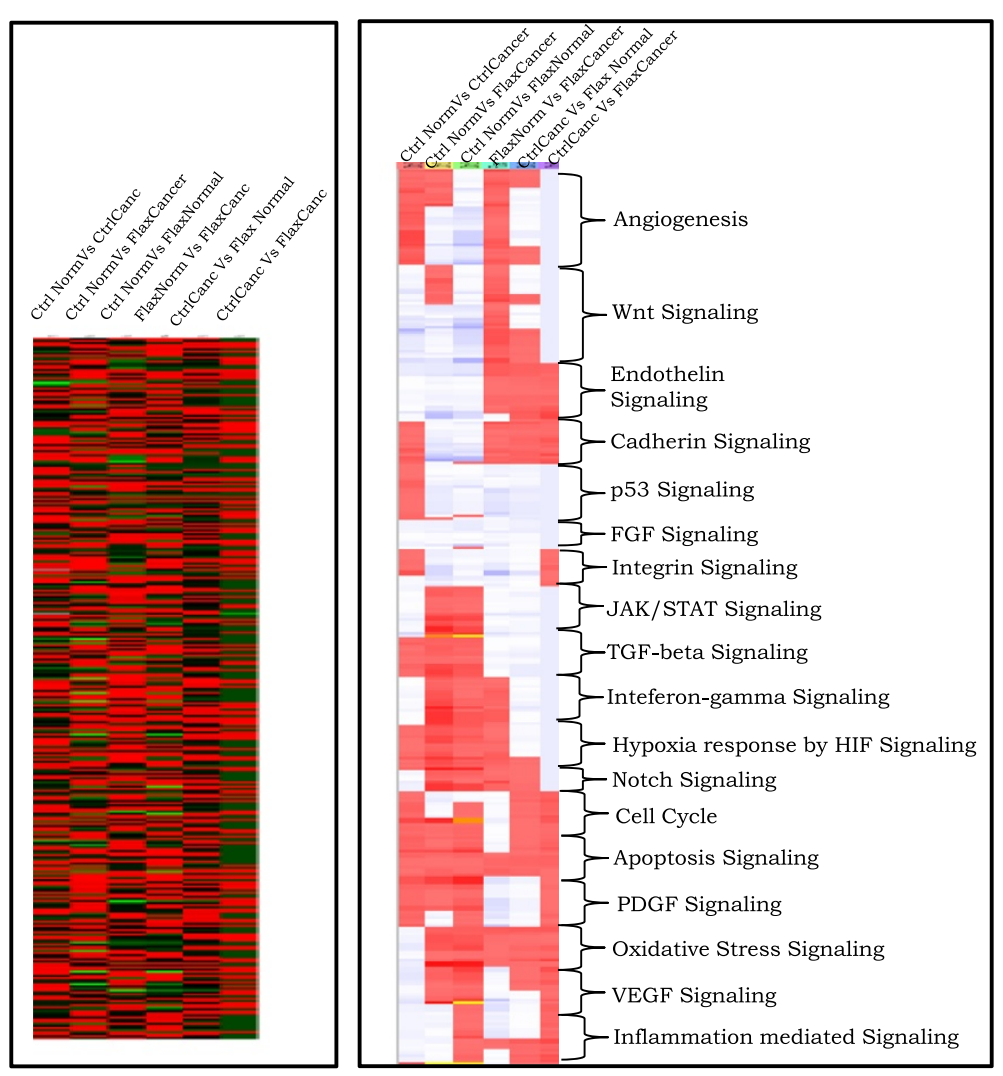

Figure 2 Microarray analysis showing the effects of flaxseed in ovarian cancer at whole genome level. Left, chicken whole genome wide heat map expression pattern at global level: All the gene probes used in the array which showed detectable level of expression during analysis were visualized using heat map to show their differential expression levels between the groups i.e. control-cancer vs. control-normal, control-cancer vs. flax-normal, control-cancer vs. flax-cancer, flax-cancer vs. flax-normal, flax-cancer vs. control normal and flax-normal vs. control normal. Right, heat map visualization of pathway associated genes: Genes representing the specific biological pathway involved in cancer progression were sorted and their expression levels were examined between the different analysis group and a heat map was generated for visualization.

expression in the ovary may give clues as to which pathways become dysregulated very early on during the transformation of normal cells toward a malignant phenotype. We have shown previously that E-cadherin is significantly upregulated in hen ovarian cancer similar to what is observed in the human disease [12]. qPCR analysis from the current study reveals that E-cadherin mRNA is decreased more than $40 \%$ in tumors from hens fed flaxseed (Figure 5) and E-cadherin protein has been shown to be decreased by $50 \%$ in tumors from flax-fed hens [22]. E-cadherin is expressed in the ovarian surface epithelium (OSE) and expression in the tumor compartment is confined to the glandular epithelial cells (Figure 6). The observation that flaxseed decreases E-cadherin in ovarian cancer reveals that flaxseed modulates very early events in neoplastic transformation.

The microarray analysis and PCR array identified an additional group of genes that were upregulated in cancer and targeted by flaxseed. These were genes encoding transcription factors involved in early development, cellfate determination and morphogenesis including $P A X 2$
[23], FOXA2 [24], MSX2 [25] and EN1 [26]. The expression of these genes was assayed in samples obtained from the five year study (Figure 5) [15]. In agreement with data from both human [27] and chicken [28], we find $P A X 2$ expression is upregulated 9-fold in ovarian cancer from control-fed hens compared to normal ovaries from control-fed hens. Additionally, we show that flaxseed attenuated this upregulation in ovarian tumors to 6-fold compared to normal ovaries. MSX2, a member of the muscle segment homeobox family, is upregulated 5 -fold in ovarian tumors from control-fed hens compared to normal ovaries. Dietary flaxseed significantly decreased this upregulation to 2-fold in ovarian tumors. FOXA2 mRNA is aberrantly over-expressed 7-fold in ovarian tumors from control-fed hens. This upregulation is decreased by flaxseed to 4-fold in ovarian tumors compared to normal ovaries. Lastly, we show that tumors from control-fed hens exhibit a 6-fold upregulation of EN1 mRNA compared to normal ovaries, and this upregulation is decreased by flaxseed to 2-fold compared to normal ovaries. In addition, the flaxseed diet has an 


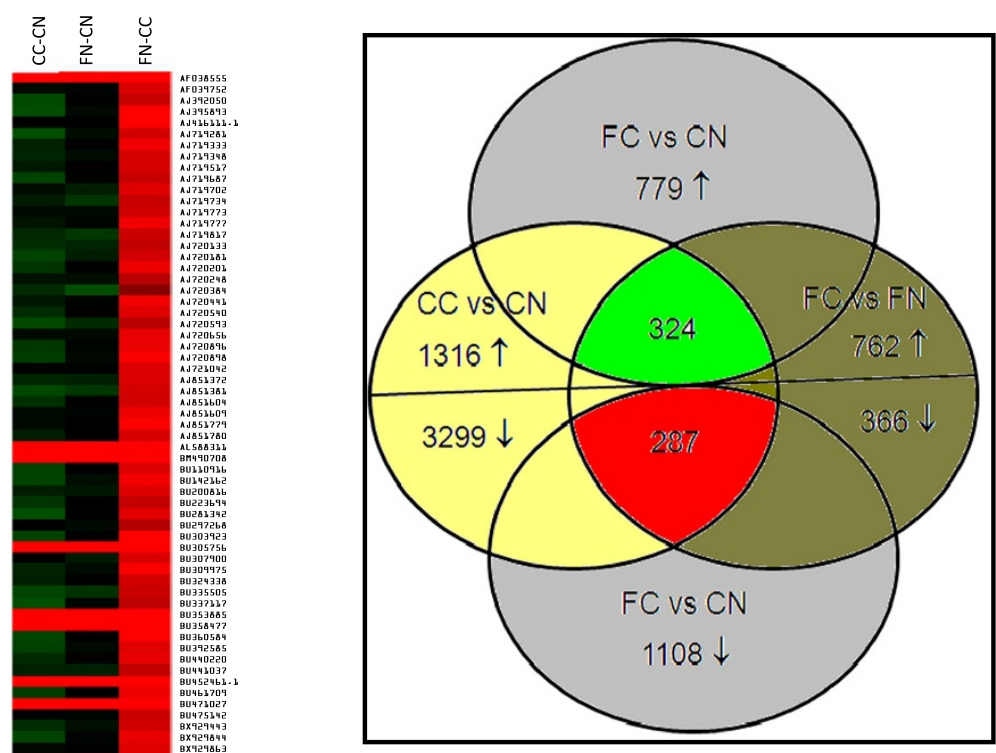

Figure 3 Analysis of genes affected by cancer and diet. Left, changes in the expression of sorted genes between flax-normal vs. control-cancer (FN-CC) was visualized by heat map. Right, Venn diagram of overlapping genes among the different data sets viz. control-cancer vs. control-normal (CC-CN), flax-cancer vs. flax-normal (FC-FN) and flax-normal vs. control-normal (FN-CN) dataset. Genes are listed in additional file 2.

inhibitory effect on the expression of $P A X 2, M S X 2$ and E-cadherin mRNA in normal ovaries in the absence of pathology. That all of these genes are significantly downregulated in tumors from flax-fed hens suggests that they may play a role in the progression of the disease.

Immunohistochemical localization of $P A X 2, F O X A 2$ and $E N 1$ reveals that they co-localize with $\mathrm{E}$-cadherin in the glandular epithelial compartment of the ovarian tumor (Figure 6). No expression of these factors can be detected prior to the expression of E-cadherin in the cortical region of the ovary, nor do they co-localize with E-cadherin in the OSE. Three of these genes play an active role in normal gland morphogenesis. In the mouse, PAX2 protein is required for Mullerian duct formation, including ductal and mesenchymal elements [23]. MSX2 expression has been reported to be increased in human ovarian endometrioid adenocarcinoma as a target of WNT signaling [29]. It has also been shown to play a role in branching morphogenesis during mouse mammary gland development through the action of BMP signaling [25]. It plays a role in both growth and apoptosis, particularly affecting the proliferative and regenerative capacity of tissue [30]. FOXA2 plays a role in mouse lung morphogenesis [31] as well as chicken oviduct development [32], where it is modulated posttranscriptionally by estrogen. It promotes epithelialization during embryogenesis [33] and has been shown to directly [34] and indirectly [35] regulate E-cadherin expression. Engrailed has been best characterized in the Drosophila wing for its role as a segment polarity gene that transcriptionally activates Hedgehog, which in turn establishes the Decapentaplegic (BMP homolog) morphogen 
Table 1 Genes included in PCR array

\begin{tabular}{|c|c|}
\hline Gene & Function \\
\hline Jun & \multirow{2}{*}{$\begin{array}{l}\text { Fos and Jun dimerize to form AP-1, } \\
\text { involved in cell proliferation, } \\
\text { differentiation, and transformation }\end{array}$} \\
\hline Fos & \\
\hline $\begin{array}{l}\text { PCNA, proliferating cell nuclear } \\
\text { antigen }\end{array}$ & $\begin{array}{l}\text { DNA synthesis, cell-cycle control, and } \\
\text { DNA-damage response and repair }\end{array}$ \\
\hline CCND1, cyclin D1 & $\begin{array}{l}\text { Regulatory subunit of CDK4 or CDK6, } \\
\text { whose activity is required for cell } \\
\text { cycle G1/S transition }\end{array}$ \\
\hline $\begin{array}{l}\text { TERT1, telomerase reverse } \\
\text { transcriptase }\end{array}$ & $\begin{array}{l}\text { Maintains telomere ends, } \\
\text { chromosomal repair }\end{array}$ \\
\hline mycN & $\begin{array}{l}\text { Transcription factor amplified or } \\
\text { overexpressed in variety of tumors }\end{array}$ \\
\hline CMYC & $\begin{array}{l}\text { Transcription factor activated upon } \\
\text { various mitogenic signals such as } \\
\text { Wnt, Shh and EGF }\end{array}$ \\
\hline gli3 & $\begin{array}{l}\text { Transcription factor mediating sonic } \\
\text { hedgehog signaling }\end{array}$ \\
\hline SOX2 & $\begin{array}{l}\text { Transcription factor with roles in } \\
\text { embryonic development, cell fate } \\
\text { determination, stem cell } \\
\text { maintenance }\end{array}$ \\
\hline Oct4 & $\begin{array}{l}\text { Involved in the self-renewal of } \\
\text { undifferentiated embryonic } \\
\text { stem cells. }\end{array}$ \\
\hline Klf4 & $\begin{array}{l}\text { Indicator of stem-like capacity in } \\
\text { embryonic stem cells }\end{array}$ \\
\hline VEGF1 & Endothelial cell mitogen \\
\hline ANGPT1, angiopoietin 1 & $\begin{array}{l}\text { Involved in vascular development } \\
\text { and angiogenesis }\end{array}$ \\
\hline CAV1, caveolin & $\begin{array}{l}\text { Scaffolding protein, possible tumor } \\
\text { suppressor }\end{array}$ \\
\hline Wnt5A & $\begin{array}{l}\text { Secreted signaling protein, activates } \\
\text { beta catenin transcriptional activity }\end{array}$ \\
\hline Wnt11 & $\begin{array}{l}\text { Secreted signaling protein, } \\
\text { implicated in oncogenesis and in } \\
\text { several developmental processes }\end{array}$ \\
\hline SNAI2, snail2 & $\begin{array}{l}\text { Transcriptional repressor involved in } \\
\text { epithelial-mesenchymal transitions } \\
\text { and has antiapoptotic activity. }\end{array}$ \\
\hline TGFbeta & $\begin{array}{l}\text { Member of a family of peptides that } \\
\text { regulate proliferation, differentiation, } \\
\text { adhesion, migration, and other } \\
\text { functions in many cell types }\end{array}$ \\
\hline IGF1, insulin like growth factor & Growth and anabolic effects \\
\hline IL2 & $\begin{array}{l}\text { Cytokine regulates lymphocyte } \\
\text { activity }\end{array}$ \\
\hline IL10 & Anti-inflammatory cytokine \\
\hline $\begin{array}{l}\text { PTGS1, COX1, prostaglandin G/H } \\
\text { synthase and cyclooxygenase) }\end{array}$ & $\begin{array}{l}\text { Converts arachidonic acid to } \\
\text { prostaglandin }\end{array}$ \\
\hline
\end{tabular}

gradient [36]. In mammals, EN2 has been shown to be dysregulated in bladder, ovarian and prostate cancers, whereas EN1 has been demonstrated in salivary gland adenoid cystic carcinoma [37]. Interestingly, Engrailed can be secreted as well as taken up by cells and urinary EN2 levels have been proposed as a marker for prostate cancer [38]. Although expression of these genes may suggest a cell or tissue of origin for ovarian cancer, an alternative interpretation may be the induction of a morphogenic process in the ovary to which a plastic transformed cell responds. Thus, EOC could conceivably develop in the ovary due to the activation of morphogens responsible for glandular differentiation acting on transformed cells. The parallel patterns of expression we observe in these genes in tumors from both control-fed and flax-fed hens suggests that formation of EOC is mediated in part by aberrant activation of a developmental program which controls branching morphogenesis, and that dietary flaxseed impedes or perturbs this program.

\section{miR-200 family is upregulated in hen ovarian cancer compared to normal ovaries and is decreased by dietary flaxseed}

It has been observed in human ovarian cancers that increased E-cadherin parallels increased levels of miR-200 family members [39]. While the function of the miR-200 family in ovarian cancer is complex, this upregulation is currently under rigorous scrutiny for potential diagnostic and prognostic value. To date, the relationship between E-cadherin and the three members of the chicken miR200 family has not been examined in chicken ovarian cancer. We measured expression levels of miR-200a, miR-200b, and miR-429 in ovarian tumors from controlfed hens and found they were upregulated 22-fold, 26-fold, and 18-fold respectively, compared to expression levels in normal ovaries. Expression levels of miR200a, miR-200b and miR-429 were upregulated 5-fold, 7-fold, and 8-fold respectively, in ovarian tumors from flax-fed hens compared to normal ovaries (Figure 7). These data show that the chicken miR200 family is upregulated in ovarian tumors and that flaxseed was able to significantly inhibit the up-regulation of all three members in ovarian cancer by 55 to $80 \%$. It has recently been shown that miR200 family members can be induced in ovarian cancer cells after exposure to oxidative stress [40]. Flaxseed acts as an antioxidant, particularly through the action of the lignan seicoisolariceresinol diglucoside, and its metabolites enterodiol and enterolactone $[41,42]$. The action of these antioxidants may account for the decreased levels of miR200 family members in the flax-fed hens. Localization of miR-200a by in situ hybridization shows that expression is confined to the glandular epithelial compartment of the ovarian tumor, reflecting the positive correlation between miR-200 expression and E-cadherin expression in hen ovarian cancer (Figure 7). Relatively few studies have shown that dietary manipulation can directly affect miRNA expression. A limited number of specific dietary constituents and phytochemicals have been identified 


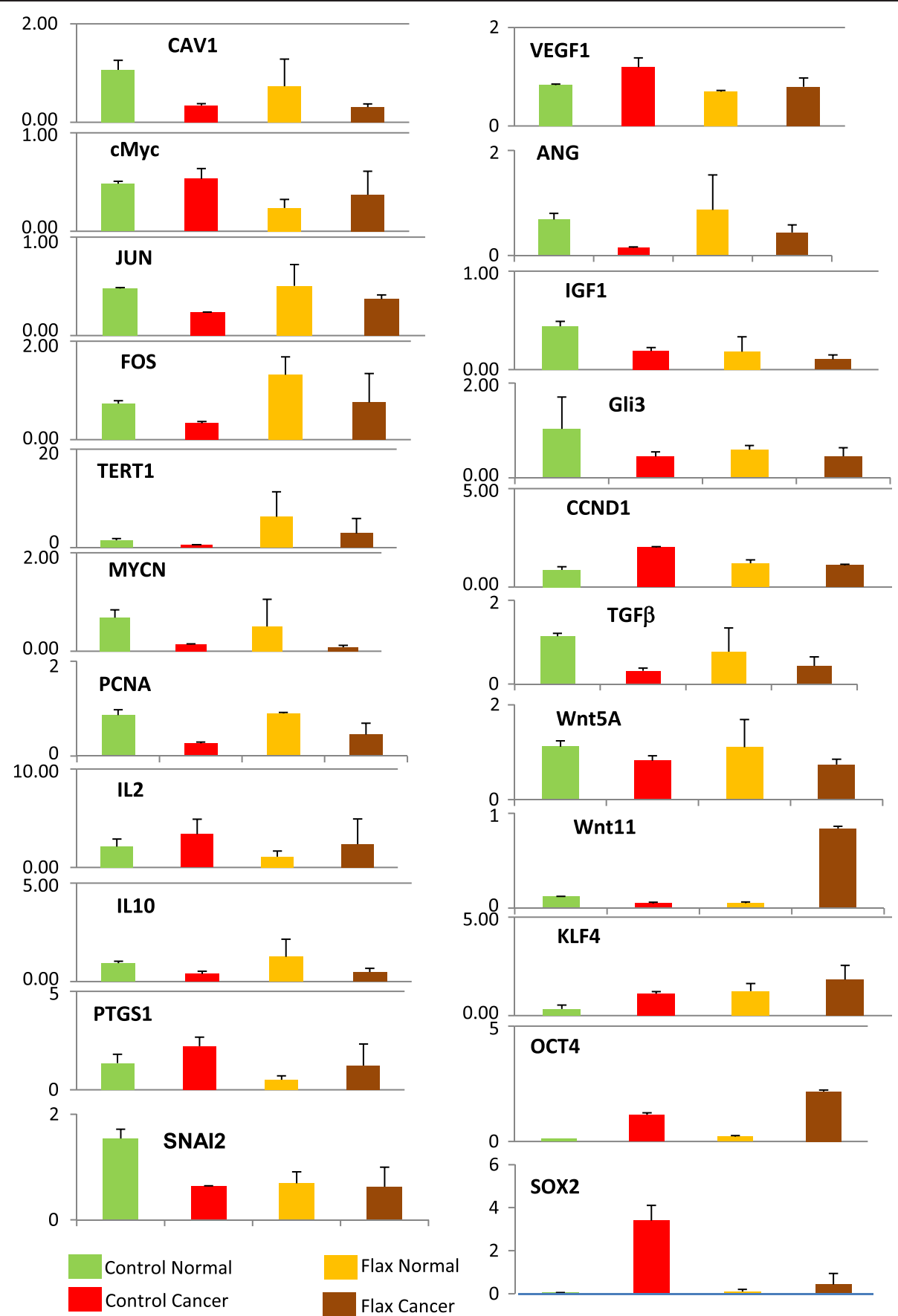

Figure 4 Real Time-PCR gene expression analysis. Selected genes were analyzed by PCR-array to validate microarray data.

which show direct or indirect chemopreventive or chemotherapeutic action by modulation of miRNA expression or activity. The majority of these studies have utilized in vitro culture systems to examine the effects of dietary constituents on miRNA expression. The few whole-animal studies that have been conducted have shown promise in their abilities to modulate miRNA expression [43]. This is the first report of dietary modulation of microRNAs in a spontaneous cancer model.

It has been well-established that the level of E-cadherin expression can reflect a balance between miR200 and ZEB1 expression [44]. The 3' untranslated region of ZEB1 mRNA has several binding sites for the miR200 family and has been shown to be targeted for degradation by 


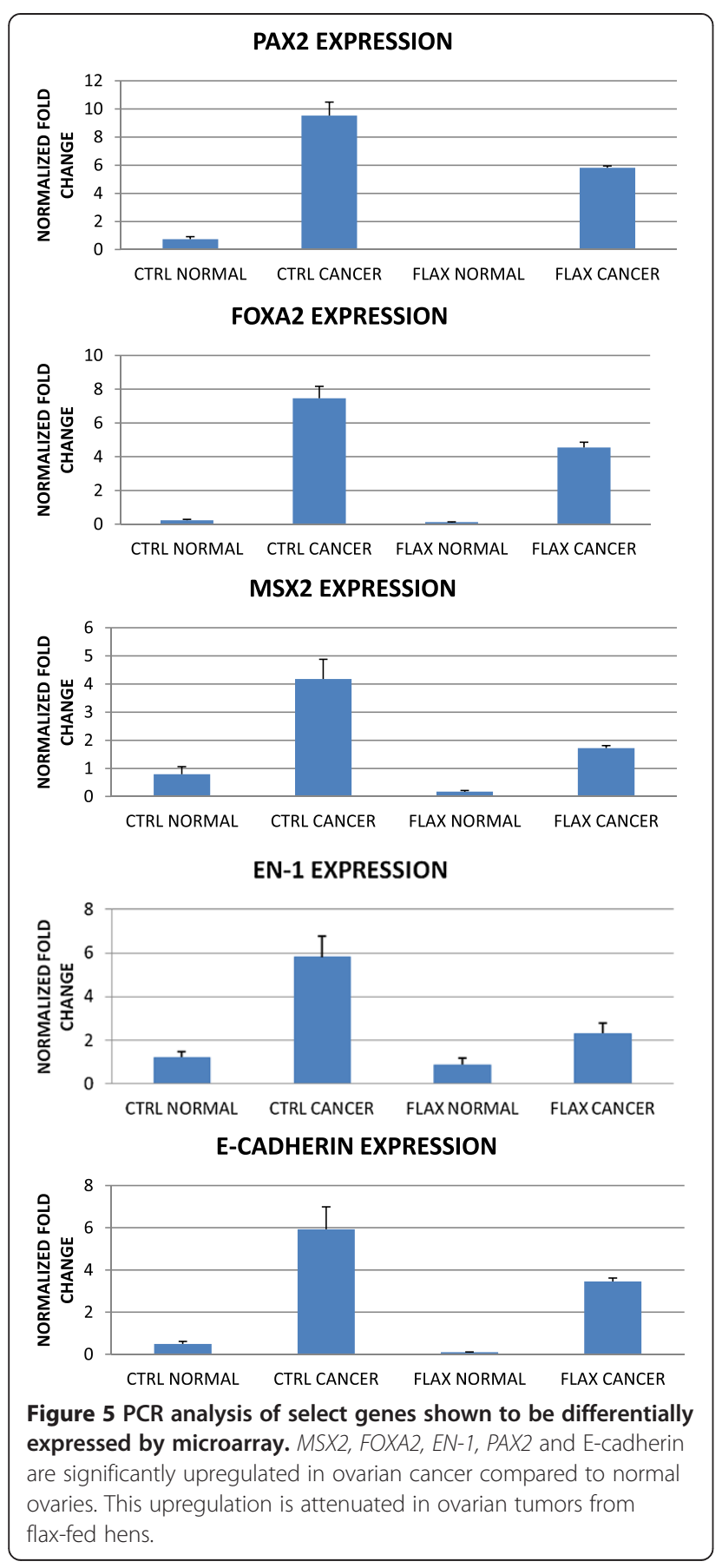

miR200. In turn, ZEB1 acts to repress transcription of both miR200 and E-cadherin [45-47]. We considered the possibility that the decrease observed in both E-cadherin and miR200 expression in tumors from flax-fed hens reflected increased ZEB1 expression. Analysis of ZEB1 mRNA by $\mathrm{qPCR}$ indicated that there was already a significant increase in ZEB1 mRNA in ovarian tumors from control-fed hens compared to normal, and a similar increase was observed in tumors from flax-fed hens compared to normal ovaries (Figure 8). Interaction between
microRNAs and their mRNA targets can be mediated by degradation of the mRNA or by sequestration from translation. Immunohistochemistry was performed to determine if ZEB1 was expressed in the tumor epithelium. Oviduct served as a positive control and no staining was observed in normal ovary (Additional file 3). Immunohistochemistry revealed that there were ZEB1 positive cells in the normal stromal compartment (Figure 8, arrows) adjacent to the tumors but not in the tumor epithelial cells, nor in the stromal cells between the glandular tumor epithelia. No difference in localization was observed between tumors from control-fed and flax-fed hens. This suggests that the effect of the flaxseed diet on E-cadherin and miR200 in ovarian tumors in the chicken is not by way of an epithelial-mesenchymal transition mechanism caused by an increase in ZEB1 expression in the epithelial compartment.

Dietary flaxseed significantly decreases expression of miR-200 family in hen ovarian cancer, but does not affect expression of miR-200 family in normal ovaries. This observation is significant in its implication that some of the chemopreventive mechanisms of flaxseed function at the epigenetic regulatory level. Indeed, whole flaxseed contains elements that exert pleiotropic actions in cancer cells by functioning as antioxidant, anti-inflammatory, and anti-estrogenic agents.

\section{Conclusions}

Microarray analysis revealed that flaxseed downregulates certain genes associated with ovarian cancer development and progression, and that pathways known to be dysregulated in ovarian cancer are targets of flaxseed action. More importantly, these data support the idea that dietary manipulation can modulate epigenetic and transcriptional changes associated with cancer development and progression. Notably, flax affects a group of genes in tumors that control branching morphogenesis during gland development, including PAX2, FOXA2, MSX2 and $E N 1$. Expression of these genes explains the glandular appearance of the tumors and is evidence of the process directing tumor growth, a process that involves proliferation and subsequent differentiation into glands. The upregulation of E-cadherin is a key feature of gland development and in these tumors is paralleled by the expression of miR-200 family members. Flaxseed downregulates all of these genes in a parallel fashion, suggesting a coordinated regulation, and without inducing an epithelial-mesenchymal transition; the epithelial morphology is maintained. Recently, stem-like epithelial cells have been identified in both ovarian surface epithelium and the distal cells of the tubal fimbriae $[48,49]$. Induction of genes involved in glandular morphogenesis may drive these stem cells to proliferate and differentiate into the ovarian cortex in response to morphogens present in 


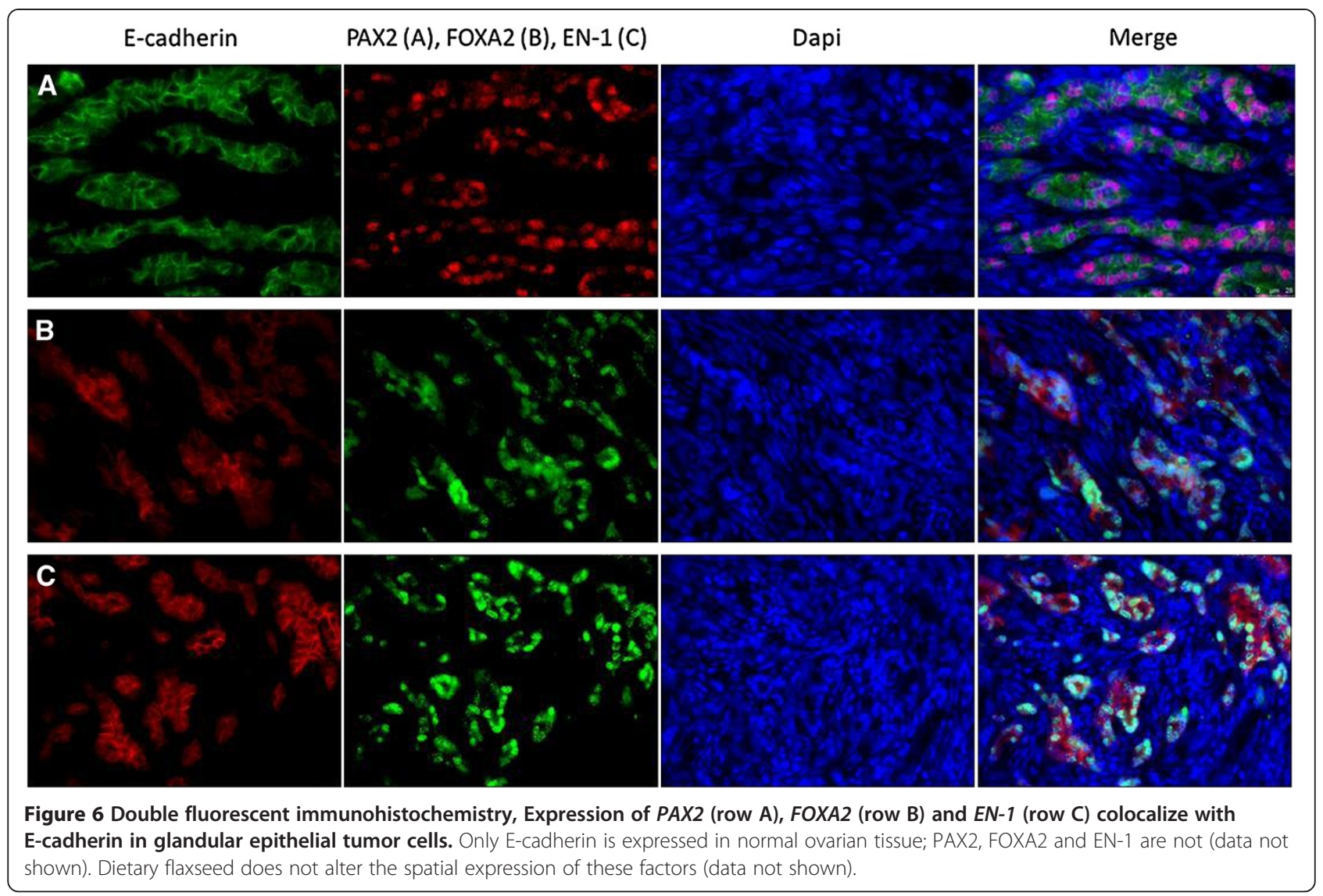

the cortex. We suggest that flaxseed reduces, but may not completely eliminate, signals from the cortex that are involved in the proliferative phase of the process of branching morphogenesis, leaving the ability to differentiate intact, thereby revealing molecular targets that will provide the foundation for clinical intervention studies.

\section{Methods}

Reagents

Antibodies: E-cadherin (BD transduction laboratories), PAX2 (Invitrogen), Dylight-488 donkey anti-mouse IgG, Dylight-549 donkey anti-rabbit IgG and Alexafluor-549 donkey anti-mouse IgG (Jackson Immunoresearch), DAPI fluorescent mounting medium (Southern Biotech). The HNF3B (HC7) monoclonal antibody was developed by Thomas Jessel and Susan Brenner-Morton and the Engrailed-1 monoclonal antibody (4D9) was developed by Corey Goodman. Both were obtained from the Developmental Studies Hybridoma Bank developed under the auspices of the NICHD and maintained by the University of Iowa, Dept. of Biology, Iowa City, IA 52242.

\section{Animal care and tissue collection}

Single-comb White Leghorn hens were maintained as previously described $[14,50]$, with review and approval of the Institutional Animal Care and Use Committees at the University of Illinois at Urbana-Champaign and Southern Illinois University at Carbondale. The one year study included 3872.5 year old hens and the five year study included 682 hens that aged 12-45 months. Hens were randomly divided into Control and Flax groups, where Control hens were fed a standard diet, while the Flax group was fed a diet supplemented with $10 \%$ flaxseed. Diet composition was previously described in detail [14]. Upon necropsy, tissues were collected and processed as described [14].

\section{Total RNA extraction and analysis}

Total RNA was extracted from ovarian tissue that was either flash-frozen in liquid nitrogen, or stored in RNAlater (Invitrogen Life Technologies, Gaithersburg, MD). TRIzol reagent (Invitrogen) was used according to manufacturer's instructions. Quantification of RNA was done using NanoDrop ND-1000 spectrophotometer measurement (NanoDrop Technologies). Integrity of total RNA was confirmed by Experion RNA StdSens Analysis (BioRad, Inc.). Biological replicates used in the microarray analysis were: 6 control normal replicates $(\mathrm{C} 7, \mathrm{C} 8, \mathrm{C} 13, \mathrm{C} 22, \mathrm{C} 23$, C31), 6 control cancer replicates (C16, C21, C30, C35, C60, C71), 6 flaxseed normal replicates (F1, F2, F5, F9, 


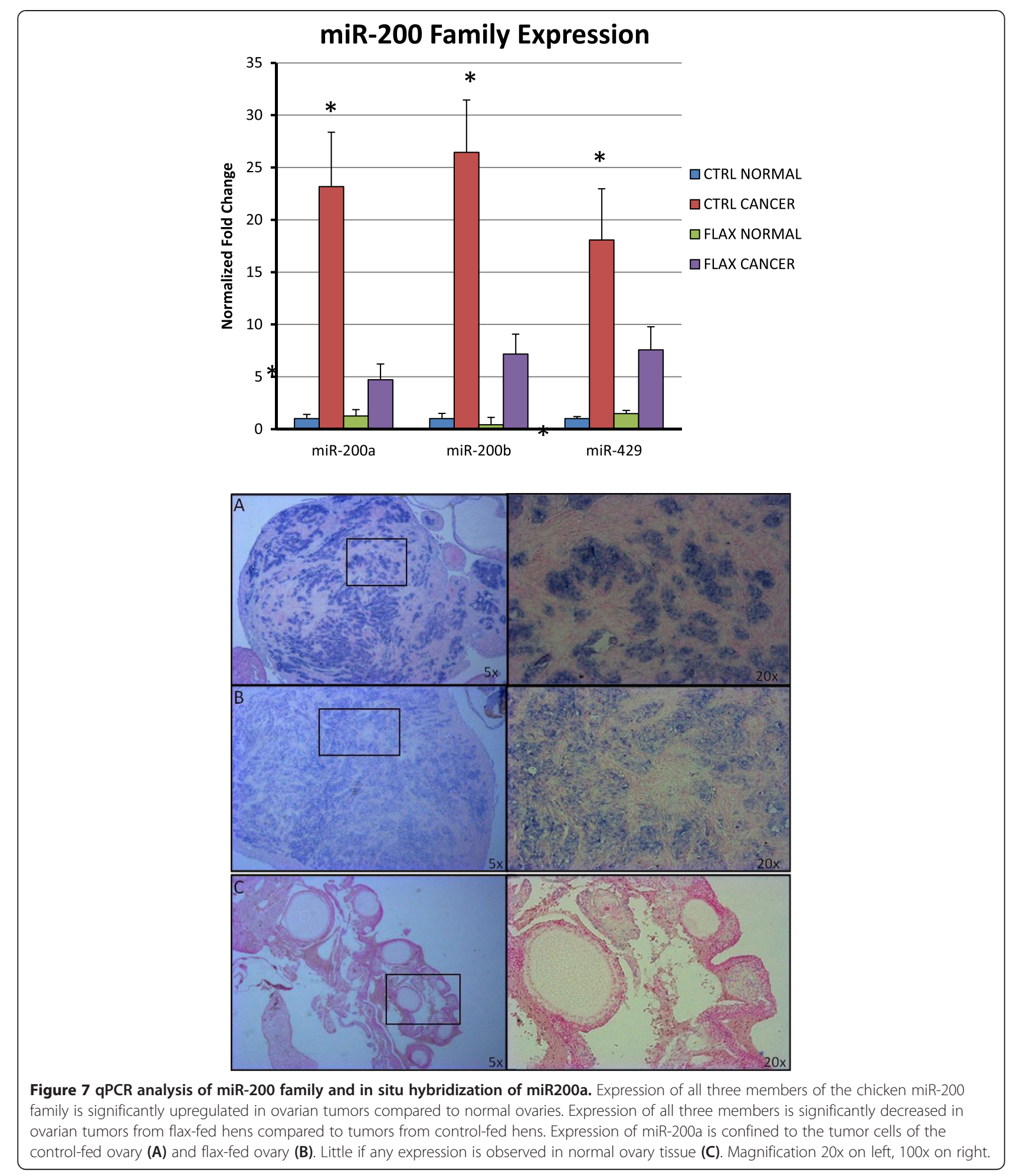

F20, F32) and 6 flaxseed cancer replicates (F11, F32, F36, F38, F86, F89) from the one year flaxseed study. The cancer replicates were of similar grade, stage and histotype.

\section{Labeling and hybridization}

The microarray procedure was conducted at the University of Illinois Urbana-Champaign at the Keck Center for Biotechnology. One microgram of total RNA was labeled 

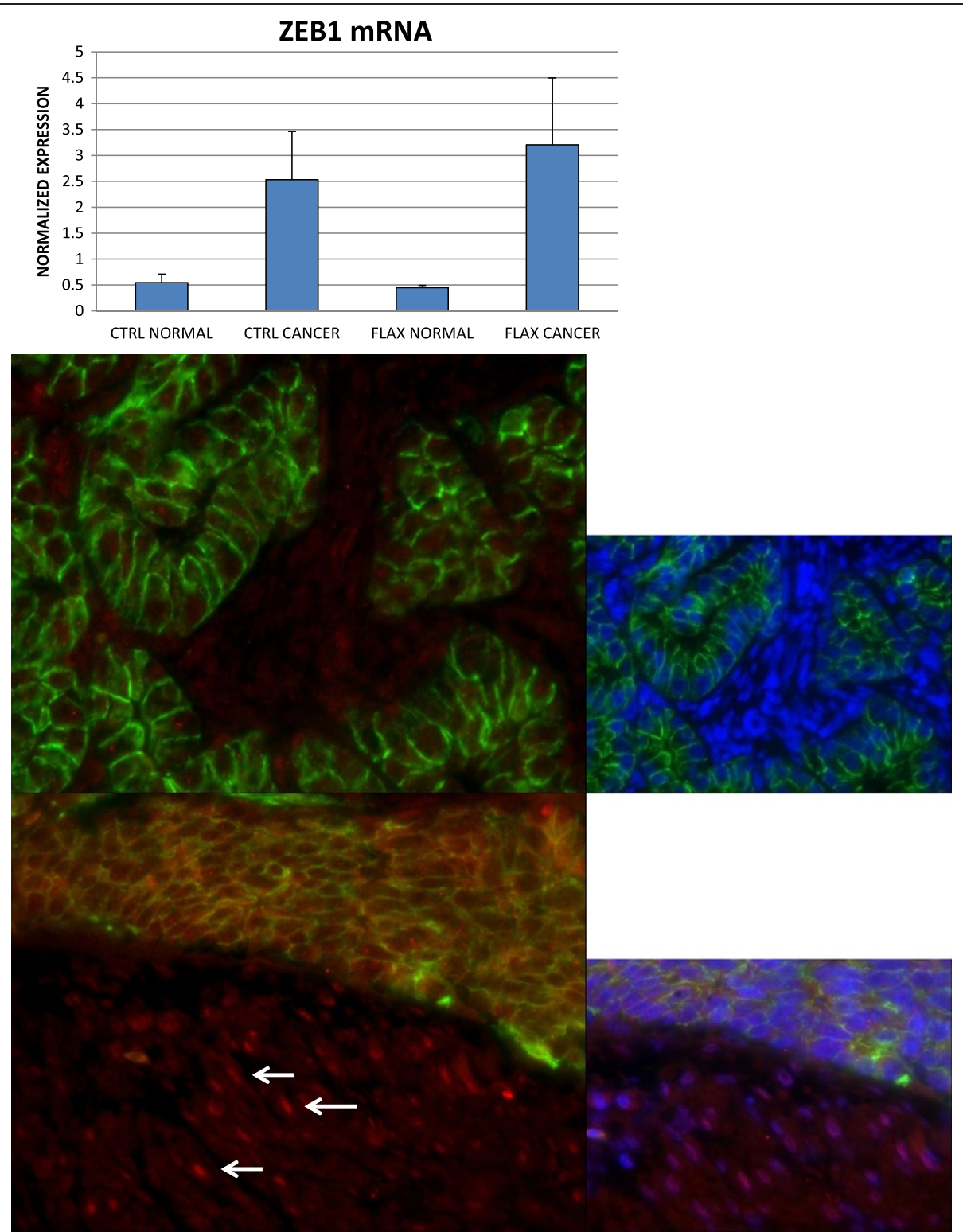

Figure 8 ZEB1 mRNA and immunohistochemistry. qPCR of ZEB1 mRNA indicates an upregulation in tumors from both control and flax fed hens but no nuclear expression by immunohistochemistry in the tumor epithelium (control-fed top, flax-fed bottom). Some nuclear expression is seen in adjacent normal stroma from flax fed hen (bottom, arrows). ZEB1 is red, E-cadherin is green, nuclei are stained with DAPI. Smaller micrographs include the blue DAPI channel. Magnification at 100x.

using the Agilent two-color QuickAmp labeling kit (Agilent Technologies) according to the manufacturer's protocol. Agilent custom $4 \times 44 \mathrm{~K}$ chicken long oligo microarray, designed by Dr. Zhou of Texas A\&M University was utilized for the array analysis [16]. Samples were hybridized using the In situ hybridization kit plus (Agilent Technologies, Palo Alto, CA, USA). Arrays were incubated at $65^{\circ} \mathrm{C}$ for 17 hours in Agilent's microarray hybridization chambers. After hybridization, arrays were washed according to the Agilent protocol. Arrays were scanned at 5- $\mu \mathrm{m}$ resolution using an Axon GenePix 4000B scanner (Molecular Devices Corporation, Sunnyvale, CA) and images were saved as TIFF format. Images were quantified using Axon GenePix 6.0 (Molecular Devices Corporation, Downingtown, PA), and data were saved as .txt files for further analysis.

\section{Data normalization and statistical analysis}

Median foreground signal intensities (no background subtraction) were normalized using Locally Weighted Linear 
Regression (LOWESS) within the R statistics package (version 2.7.2) using the "VSN" method in limma (version 2.14.7) to remove signal intensity-dependent dye bias. Spots with -100 flags were weighted zero before normalization. $P$ value and fold changes between each comparison for each gene were calculated. Microarray data are MIAME compliant and available in Gene Expression Omnibus (GEO, http://www.ncbi.nlm.nih.gov/geo/) through the accession number GSE40376. Differentially expressed genes were identified by setting the significance level to a false discovery rate of $<0.1$.

\section{Bioinformatic analysis}

Annotations were done using Database for Annotation, Visualization and Integrated Discovery (DAVID) tool [51,52]. We applied various bioinformatics tools such as Multiple Experimental Viewer for the heatmap [53], and Ingenuity Pathway Analysis (Ingenuity Systems, www. ingenuity.com). Functional classification of these genes was carried out using the gene expression analysis tool PANTHER (Protein ANalysis THrough Evolutionary Relationships) [54,55] and Gene Ontology Enrichment Analysis Software Toolkit [56] for analysis.

\section{Microarray data sorting and gene expression analysis}

Comparing the gene expression levels of the groups, the threshold level was set at $>2$ and $<2$ fold differences for the analysis. Differentially expressed genes in controlcancer vs. control-normal (CC-CN) and flax-cancer vs. flax-normal (FC-FN) constituted primary gene dataset. Then these primary datasets of CC-CN and FC-FN were compared which resulted in a secondary dataset consisting of 324 common and 287 uncommon genes of these two groups. The common genes signify that these genes are crucial in cancer progression and unaffected by flaxseed, whereas uncommon genes present in $\mathrm{CC}-\mathrm{CN}$ group may be possible targets of flaxseed. To identify these potential flaxseed target genes, the uncommon genes in $\mathrm{CC}-\mathrm{CN}$ were compared with flax-normal vs control-normal (FN-CN) dataset which generated a final list of 118 common genes.

\section{PCR-array}

Four biological replicate samples from control-normal, control-cancer, flax-normal and flax-cancer were used for analysis. Total RNA was transcribed into cDNA using qScript DNA supermix. A customized 384 well StellARray (Cat\#00194810) for Gallus gallus was purchased from Bar Harbor BioTechnology. A total of 44 target genes (including 4 housekeeping genes) were selected for analysis. Real-time PCR was performed using cDNA and EvaGeen mix (BioRad, Inc.) in a 384 well plate with primer mix for selected genes. The reaction and signal were measured using BioRad CFX manager software (BioRad Inc.). The expression levels were calculated as relative expression normalized to the expression levels of the housekeeping genes TATA box binding protein 1 (TBP1), Ribosomal protein L4 (RPL4), Glyceraldehyde 3-phosphate dehydrogenase (GAPDH) and Succinate dehydrogenase complex, subunit A (SDHA).

\section{CDNA Synthesis and qPCR analysis of mRNA Targets}

First-strand cDNA synthesis was performed using total RNA and qScript cDNA Supermix (Quanta Biosciences 95048) according to manufacturer's instructions. qPCR was performed using SsoFast EvaGreen Supermix (BioRad 172-5203). Reactions were 10ul and used $400 \mathrm{~nm}$ symmetric primer mix. Amplification conditions were as follows: 95C $5 \mathrm{~s}, 40$ cycles for 95C $5 \mathrm{~s}, 58-68 \mathrm{C} 2 \mathrm{~s}$. Expression analysis was performed using BioRad CFX Manager Software. mRNA levels were normalized to two stably expressed reference genes, SDHA and RPL4.

\section{Double-fluorescent Immunohistochemistry}

Ovary tissue was collected from hens in the five year study, processed, fixed in NBF and paraffin-embedded as previously described [50]. Five micrometer sections were mounted onto charged Superfrost slides, deparaffined in xylene and rehydrated in graded ethanol solutions. Antigen retrieval was performed by heating slides under pressure of $15 \mathrm{psi}$ in $0.1 \mathrm{M}$ sodium citrate for 20 minutes. Slides were blocked with phosphate buffered saline/0.1\% Tween-20 (PBST) and 5\% fetal calf serum for 2 hours. Following blocking, sections stained for PAX2 and E-cadherin were incubated overnight with both rabbit anti-mouse PAX2 at 1:200 and mouse anti-human Ecadherin at 1:500 in PBST with 5\% fetal calf serum. Slides were washed in PBST and incubated with both Dylight488 donkey anti-mouse IgG and Dylight-549 donkey anti-rabbit IgG) at 1:200 for 2 hours. Sections stained for E-cadherin/EN-1 and E-cadherin/FOXA2 were incubated with anti- E-cadherin overnight, washed in PBST and then incubated with Alexafluor-549 donkey anti-mouse IgG at 1:200 for 2 hours. A second overnight incubation with either anti-HNF3beta or anti-Engrailed-1 at 1:10 in PBST and $5 \%$ fetal calf serum, followed by incubation with Dylight 488-conjugated donkey anti-mouse IgG at 1:200 for 2 hours completed the double-labeling. All slides were mounted with DAPI fluorescent mounting medium and visualized by confocal microscopy using a Leica model DM5500Q microscope using filters A4, Y5, and L5, and images were captured with a Leica DFC365 FX camera. Dual images were produced using Leica Application Suite-Advanced fluorescence version 2.6.0.7266.

\section{miRNA quantification}

Total RNA was isolated from flash-frozen ovary tissue from the five year study using Tri Reagent (Ambion). First-strand cDNA synthesis was performed using Universal cDNA 
synthesis kit (Exiqon 203301). miRNA expression was quantified using SYBR Green master mix, Universal RT kit (Exiqon 203420). Locked nucleic acid primers for miR-200a (Exiqon 204707), miR-200b (custom Exiqon primer set), and miR-429 (Exiqon 205068) were used for quantification. qPCR values were normalized to two reference miRNAs stably expressed across the sample population, miR-460 (Exiqon) and miR-455 (Exiqon). Six samples were analyzed per group. Statistical analysis using one-way ANOVA followed by Student-Newman-Keuls post test was performed using GraphPad Instat program. p values of 0.05 or less were considered significant.

\section{miRNA in situ hybridization}

In situ hybridization for miR-200a was performed as previously described [57] with modifications. Briefly, formalinfixed, paraffin-embedded tissues from the five year study were sectioned at 5 micrometers and mounted onto positively-charged Superfrost slides. Sections were deparaffined in Histoclear and rehydrated through graded ethanol solutions. Sections were then digested with proteinase $\mathrm{K}$ (20ug/ml for 15 minutes) and acetylated. miR-200a double-DIG-labeled LNA probe (Exiqon) was diluted to $20 \mathrm{nM}$ in hybridization buffer (Roche) and sections were hybridized overnight at $54^{\circ} \mathrm{C}$. Following stringency washes, sections were blocked and incubated with goat anti-digoxin antibody conjugated to AP at 1:500 for 16 hours. Color development was performed using BCIP/NBT (Roche) in NTMT, 10\% PVA and Levamisole (Sigma) for 30 hours. Sections were counterstained with nuclear fast red and mounted for visualization using a Leica model DM IL microscope and DFC 400 camera.

\section{Availability of supporting data}

Microarray data are MIAME compliant and available in Gene Expression Omnibus (GEO, http://www.ncbi.nlm. nih.gov/geo/) through the accession number GSE40376.

\section{Additional files}

Additional file 1: Relative expression of 337 genes related to the pathogenesis of ovarian cancer in pair-wise comparisons. ${ }^{a} \mathrm{CCvSCN}-$ control cancer vs control normal. ${ }^{b} \mathrm{FCvsCN}$-flax cancer vs control normal. ${ }^{c}$ FC vsCC-flax cancer vs control cancer. ${ }^{d}$ FCvsFN-flax cancer vs flax normal. eFNvsCC - flax normal vs control cancer. ${ }^{\mathrm{f} F N v s C N}$ - flax normal vs control normal.

Additional file 2: 118 flaxseed-responsive genes involved in ovarian cancer. ${ }^{\mathrm{C}} \mathrm{CC}-\mathrm{CN}$ - control-cancer vs. control-normal.

${ }^{b}$ FC-FN-flax-cancer vs. flax-normal. ${ }^{c}$ FN-CN-flax-normal vs control-normal.

Additional file 3: ZEB1 expression in oviduct and ovary, Top, expression of E-cadherin (green) in epithelium and ZEB1 (red) in adjacent stromal compartment of oviduct. Middle, expression of smooth muscle actin (green) and ZEB1 (red) in the stromal compartment of the oviduct. Bottom, E-cadherin expression in the ovarian surface epithelium (green), no specific staining for ZEB1 (red) in normal ovary. Nuclei are stained with DAPI.
Competing interests

The authors declare that they have no competing interests.

\section{Authors' contributions}

DBH conceived of and designed the microarray study, NKK performed the bioinformatic analysis of the microarray and PCR array, $\mathrm{KHH}$ assisted in the design of the PCR array, SCS carried out the PCR analysis of miRNAs and mRNAs and performed the in situ hybridization and immunohistochemistry. All four authors helped to draft and revise the manuscript and have read and approved the final version.

\section{Acknowledgements}

We wish to thank Dr. Sharon Stack for her critical reading of the manuscript, and Stacey McGee for the Zeb1 immunohistochemistry.

This work was supported by NIH/NCCAM AT005295 (DBH), NIH/NCCAM AT004085 (DBH); NIH/NCl CA133915 (DBH), Art Erhmann Cancer Fund, Fraternal Order of Eagles $(\mathrm{KHH})$ and startup funds from Southern Illinois University School of Medicine $(\mathrm{KHH})$.

\section{Author details}

${ }^{1}$ Department of Obstetrics and Gynecology, Southern Illinois University at Carbondale, School of Medicine, Life Science III, (M/C 6512), 1135 Dr., Carbondale, Lincoln, IL 62901, USA. ²Department of Physiology, Southern Illinois University at Carbondale, School of Medicine, Life Science III, (M/C 6512), 1135 Dr., Carbondale, Lincoln, IL 62901, USA. ${ }^{3}$ Current address CSIR Central Food Technological Research Institute, Mysore, KA 570020, India.

Received: 27 November 2013 Accepted: 5 June 2014

Published: 24 August 2014

\section{References}

1. Vaughan S, Coward JI, Bast RC Jr, Berchuck A, Berek JS, Brenton JD, Coukos G, Crum CC, Drapkin R, Etemadmoghadam D, Friedlander M, Gabra H, Kaye SB, Lord CJ, Lengyel E, Levine DA, McNeish IA, Menon U, Mills GB, Nephew KP, Oza AM, Sood AK, Stronach EA, Walczak H, Bowtell DD, Balkwill FR: Rethinking ovarian cancer: recommendations for improving outcomes. Nat Rev Cancer 2011, 11(10):719-725.

2. Wiseman M: The second world cancer research fund/American institute for cancer research expert report. Food, nutrition, physical activity, and the prevention of cancer: a global perspective. Proc Nutr Soc 2008, 67(03):253-256.

3. Coussens LM, Werb Z: Inflammation and cancer. Nature 2002, 420(6917):860-867.

4. Wang L-Q: Mammalian phytoestrogens: enterodiol and enterolactone. J Chromatogr B 2002, 777(1-2):289-309.

5. Johnson PA, Giles JR: The hen as a model of ovarian cancer. Nat Rev Cancer 2013, 13(6):432-436.

6. Lengyel E, Burdette JE, Kenny HA, Matei D, Pilrose J, Haluska P, Nephew KP, Hales DB, Stack MS: Epithelial ovarian cancer experimental models. Oncogene 2013. August 12 [Epub ahead of print].

7. Fredrickson TN: Ovarian tumors of the hen. Environ Health Perspect 1987, 73:35-51.

8. Barua A, Bitterman P, Abramowicz JS, Dirks AL, Bahr JM, Hales DB, Bradaric MJ, Edassery SL, Rotmensch J, Luborsky JL: Histopathology of ovarian tumors in laying hens: a preclinical model of human ovarian cancer. Int J Gynecol Cancer 2009, 19(4):531-539.

9. Hakim AA, Barry CP, Barnes HJ, Anderson KE, Petitte J, Whitaker R, Lancaster JM, Wenham RM, Carver DK, Turbov J, Berchuck A, Kopelovich L, Rodriguez GC: Ovarian adenocarcinomas in the laying hen and women share similar alterations in p53, ras, and HER-2/neu. Cancer Prev Res (Phila) 2009, 2(2):114-121.

10. Jackson E, Anderson K, Ashwell C, Petitte J, Mozdziak PE: CA125 expression in spontaneous ovarian adenocarcinomas from laying hens. Gynecol Oncol 2007, 104(1):192-198.

11. Zhuge Y, Lagman JA, Ansenberger K, Mahon CJ, Daikoku T, Dey SK, Bahr JM, Hales DB: CYP1B1 expression in ovarian cancer in the laying hen Gallusdomesticus. Gynecol Oncol 2009, 112(1):171-178.

12. Ansenberger $K$, Zhuge $Y$, Lagman JA, Richards C, Barua A, Bahr JM, Hales DB: E-cadherin expression in ovarian cancer in the laying hen, Gallus domesticus, compared to human ovarian cancer. Gynecol Oncol 2009, 113(3):362-369. 
13. Hales DB, Zhuge Y, Lagman JA, Ansenberger K, Mahon C, Barua A, Luborsky $J$, Bahr JM: Cyclooxygenases expression and distribution in the normal ovary and their role in ovarian cancer in the domestic hen (Gallus domesticus). Endocrine 2008, 33(3):235-244.

14. Ansenberger K, Richards C, Zhuge Y, Barua A, Bahr JM, Luborsky JL, Hales DB: Decreased severity of ovarian cancer and increased survival in hens fed a flaxseed-enriched diet for 1 year. Gynecol Oncol 2010, 117(2):341-347.

15. Eilati $E$, Bahr JM, Hales DB: Long term consumption of flaxseed enriched diet decreased ovarian cancer incidence and prostaglandin E2 in hens. Gynecol Oncol 2013, 130(3):620-628

16. Li X, Chiang Hl, Zhu J, Dowd SE, Zhou H: Characterization of a newly developed chicken 44 K Agilent microarray. BMC Genomics 2008, 9:60,

17. Landen CN Jr, Birrer MJ, Sood AK: Early events in the pathogenesis of epithelial ovarian cancer. J Clin Oncol 2008, 26(6):995-1005.

18. Zhang J, Chen YH, Lu Q: Pro-oncogenic and anti-oncogenic pathways: opportunities and challenges of cancer therapy. Future Oncol 2010, 6(4):587-603.

19. Hanahan D, Weinberg RA: Hallmarks of cancer: the next generation. Cell 2011, 144(5):646-674.

20. Takahashi K, Yamanaka S: Induction of pluripotent stem cells from mouse embryonic and adult fibroblast cultures by defined factors. Cell 2006, 126(4):663-676.

21. Hudson LG, Zeineldin R, Stack MS: Phenotypic plasticity of neoplastic ovarian epithelium: unique cadherin profiles in tumor progression. Clin Exp Metastasis 2008, 25(6):643-655.

22. Ansenberger K: The Laying hen and Flaxseed: A Model for Dietary Intervention of Human Ovarian Cancer. Ph.D. Chicago: University of Illinois at Chicago, Health Sciences Center; 2010

23. Torres M, Gomez-Pardo E, Dressler GR, Gruss P: Pax-2 controls multiple steps of urogenital development. Development 1995, 121(12):4057-4065.

24. Bazer FW: Uterine adenogenesis and pregnancy: multiple roles for Foxa2 in mice. Biol Reprod 2010, 83(3):319-321.

25. Satoh K, Ginsburg E, Vonderhaar BK: Msx-1 and Msx-2 in mammary gland development. J Mammary Gland Biol Neoplasia 2004, 9(2):195-205.

26. Logan C, Hornbruch A, Campbell I, Lumsden A: The role of Engrailed in establishing the dorsoventral axis of the chick limb. Development 1997, 124(12):2317-2324

27. Tung CS, Mok SC, Tsang YT, Zu Z, Song H, Liu J, Deavers MT, Malpica A, Wolf JK, Lu KH, Gershenson DM, Wong KK: PAX2 expression in low malignant potential ovarian tumors and low-grade ovarian serous carcinomas. Mod Pathol 2009, 22(9):1243-1250.

28. Trevino LS, Giles JR, Wang W, Urick ME, Johnson PA: Gene expression profiling reveals differentially expressed genes in ovarian cancer of the hen: support for oviductal origin? Horm Cancer 2010, 1(4):177-186.

29. Zhai $Y$, lura $A$, Yeasmin $S$, Wiese $A B$, Wu R, Feng $Y$, Fearon ER, Cho KR: MSX2 is an oncogenic downstream target of activated WNT signaling in ovarian endometrioid adenocarcinoma. Oncogene 2011, 30(40):4152-4162.

30. Bendall AJ, Abate-Shen C: Roles for Msx and Dlx homeoproteins in vertebrate development. Gene 2000, 247(1-2):17-31.

31. Wan H, Dingle $S, X u$ Y, Besnard V, Kaestner KH, Ang S-L, Wert S, Stahlman MT, Whitsett JA: Compensatory Roles of Foxa1 and Foxa2 during Lung Morphogenesis. J Biol Chem 2005, 280(14):13809-13816.

32. Berger RR, Sanders MM: Estrogen modulates HNF-3beta mRNA levels in the developing chick oviduct. DNA Cell Biol 2000, 19(2):103-112.

33. Burtscher I, Lickert H: Foxa2 regulates polarity and epithelialization in the endoderm germ layer of the mouse embryo. Development 2009, 136(6):1029-1038.

34. Liu Y-N, Lee W-W, Wang C-Y, Chao T-H, Chen Y, Chen JH: Regulatory mechanisms controlling human E-cadherin gene expression. Oncogene 2005, 24(56):8277-8290

35. Song Y, Washington MK, Crawford HC: Loss of FOXA1/2 is essential for the epithelial-to-mesenchymal transition in pancreatic cancer. Cancer Res 2010, 70(5):2115-2125.

36. Hidalgo A: Growth and patterning from the engrailed interface. Int J Dev Biol 1998, 42(3):317-324.

37. McGrath SE, Michael A, Pandha H, Morgan R: Engrailed homeobox transcription factors as potential markers and targets in cancer. FEBS Lett 2013, 587(6):549-554

38. Morgan R, Boxall A, Bhatt A, Bailey M, Hindley R, Langley S, Whitaker HC, Neal DE, Ismail M, Whitaker H, Annels N, Michael A, Pandha H: Engrailed-2
(EN2): a tumor specific urinary biomarker for the early diagnosis of prostate cancer. Clin Cancer Res 2011, 17(5):1090-1098.

39. van Jaarsveld MT, Helleman J, Berns EM, Wiemer EA: MicroRNAs in ovarian cancer biology and therapy resistance. Int J Biochem Cell Biol 2010, 42(8):1282-1290

40. Mateescu B, Batista L, Cardon M, Gruosso T, de Feraudy Y, Mariani O, Nicolas A, Meyniel J-P, Cottu P, Sastre-Garau X, Mechta-Grigoriou F: miR-141 and miR-200a act on ovarian tumorigenesis by controlling oxidative stress response. Nat Med 2011, 17(12):1627-1635.

41. Prasad K: Antioxidant activity of secoisolariciresinol diglucoside-derived metabolites, secoisolariciresinol, Enterodiol, and enterolactone. Int $J$ Angiol 2000, 9(4):220-225.

42. Kivelä $A M$, Kansanen $E$, Jyrkkänen $H-K$, Nurmi $T$, Ylä-Herttuala $S$, Levonen A-L: Enterolactone induces heme oxygenase-1 expression through nuclear factor-E2-related factor 2 activation in endothelia cells. J Nutr 2008, 138(7):1263-1268.

43. Parasramka MA, Ho E, Williams DE, Dashwood RH: MicroRNAs, diet, and cancer: new mechanistic insights on the epigenetic actions of phytochemicals. Mol Carcinog 2012, 51(3):213-230.

44. Cano A, Nieto MA: Non-coding RNAs take centre stage in epithelial-tomesenchymal transition. Trends Cell Biol 2008, 18(8):357-359.

45. Burk U, Schubert J, Wellner U, Schmalhofer O, Vincan E, Spaderna S, Brabletz T: A reciprocal repression between ZEB1 and members of the miR-200 family promotes EMT and invasion in cancer cells. EMBO Rep 2008, 9(6):582-589.

46. Gregory PA, Bert AG, Paterson EL, Barry SC, Tsykin A, Farshid G, Vadas MA, Khew-Goodall Y, Goodall GJ: The miR-200 family and miR-205 regulate epithelial to mesenchymal transition by targeting ZEB1 and SIP1. Nat Cell Biol 2008, 10(5):593-601.

47. Park SM, Gaur AB, Lengyel E, Peter ME: The miR-200 family determines the epithelial phenotype of cancer cells by targeting the E-cadherin repressors ZEB1 and ZEB2. Genes Dev 2008, 22(7):894-907.

48. Auersperg $\mathrm{N}$ : The stem-cell profile of ovarian surface epithelium is reproduced in the oviductal fimbriae, with increased stem-cel marker density in distal parts of the fimbriae. Int J Gynecol Pathol 2013, 32(5):444-453.

49. Paik DY, Janzen DM, Schafenacker AM, Velasco VS, Shung MS, Cheng D, Huang J, Witte ON, Memarzadeh S: Stem-like epithelial cells are concentrated in the distal end of the fallopian tube: a site for injury and serous cancer initiation. Stem Cells 2012, 30(11):2487-2497.

50. Eilati E, Pan L, Bahr JM, Hales DB: Age dependent increase in prostaglandin pathway coincides with onset of ovarian cancer in laying hens. Prostaglandins Leukot Essent Fatty Acids 2012, 87(6):177-184.

51. da Huang W, Sherman BT, Lempicki RA: Systematic and integrative analysis of large gene lists using DAVID bioinformatics resources. Nat Protoc 2009, 4(1):44-57.

52. da Huang W, Sherman BT, Lempicki RA: Bioinformatics enrichment tools: paths toward the comprehensive functional analysis of large gene lists. Nucleic Acids Res 2009, 37(1):1-13.

53. Saeed Al, Sharov V, White J, Li J, Liang W, Bhagabati N, Braisted J, Klapa M, Currier T, Thiagarajan M, Sturn A, Snuffin M, Rezantsev A, Popov D, Ryltsov A, Kostukovich E, Borisovsky I, Liu Z, Vinsavich A, Trush V, Quackenbush J: TM4: a free, open-source system for microarray data management and analysis. Biotechniques 2003, 34(2):374-378.

54. $\mathrm{Mi} \mathrm{H}$, Thomas P: PANTHER pathway: an ontology-based pathway database coupled with data analysis tools. Methods Mol Biol 2009, 563:123-140.

55. Mi H, Muruganujan A, Casagrande JT, Thomas PD: Large-scale gene function analysis with the PANTHER classification system. Nat Protoc 2013, 8(8):1551-1566.

56. Zheng Q, Wang XJ: GOEAST: a web-based software toolkit for Gene Ontology enrichment analysis. Nucleic Acids Res 2008, 36(Web Server issue):W358-W363

57. Bany B, Simmons D: Non-Radioactive in Situ Hybridizaion: Optimization for Tissue Sections from Pregnant Uteri and Placenta During the First Half of Pregnancy. In The Guide for Investigation of Mouse Pregnancy. Edited by Croy B, Yamada A, DeMayo F, Adamson S. Amsterdam: Elsevier; 2013:591-603.

doi:10.1186/1471-2164-15-709

Cite this article as: Hales et al:: Uncovering molecular events associated with the chemosuppressive effects of flaxseed: a microarray analysis of the laying hen model of ovarian cancer. BMC Genomics 2014 15:709. 